\title{
Renovação conservadora no Brasil: efeito perdurante da escravidão
}

Conservative renewal in Brazil: lasting effect of slavery

Renovación conservadora en Brasil: el efecto perdurable de la esclavitud

Luzia de Kassia Rocha de Souza ${ }^{1}$

${ }^{1}$ Mestra em Geografia pela Universidade Federal da Grande Dourados (UFGD). Especialista em Educação e Direitos Humanos pela Pontifícia Universidade Católica de Goiás (PUC Goiás). Assistente social pela Universidade Estadual do Tocantins (UNITINS). E-mail: luziakass@gmail.com, ORCID: http://orcid.org/0000-0002-6061-0893 
SOUZA, Jessé. A elite do atraso: da escravidão à Lava Jato. Rio de Janeiro: Leya, 2017.

A presente resenha aduz elementos cruciais para a compreensão da conjuntura atual do Brasil, aludidos no livro "A elite do atraso: da escravidão à Lava Jato". A obra analisada é um ensaio do sociólogo Jessé de Souza, doutor em Sociologia pela Universidade de Heidelberg, professor da Universidade Federal do ABC e escritor. Presidente do Instituto de Pesquisa Econômica Aplicada (IPEA) entre 2015 e 2016, coordenou pesquisas de amplitude nacional sobre classes e desigualdade social. Autor de 27 livros, entre os quais estão: "A ralé brasileira: quem é e como vive" (2009), "A tolice da inteligência brasileira" (2015) e "A radiografia do golpe" (2016).

O livro resenhado é um ensaio publicado recentemente, instigante e provocativo nos contornos das Ciências Sociais (Sociologia, Ciência Política e Antropologia). Traz importantes reflexões com o objetivo de criticar a interpretação dominante sobre a leitura histórica e factual da realidade brasileira. Nesta perspectiva, Jessé de Souza estabelece um quadro histórico permeado por ampla influencia teórica, artística, religiosa e midiática. É uma leitura imprescindível, pela necessidade ocorrente de debate e reflexão sobre o contexto político, econômico, social e cultural do país. As reflexões embasam-se em leitura histórica, entretanto, em uma perspectiva crítica, sobretudo a respeito das influências teóricas e artísticas que insuflaram a perpetuação da dominação de uma classe social sobre a outra. Dominação esta que, alicerçada e sedimentada por meio de determinadas ideias, naturalizaram a submissão excludente cunhada em racismo no Brasil.

Para cumprir seu objetivo, Souza (2017) elabora a abordagem sob forma de resposta crítica ao clássico "Raízes do Brasil", de Sérgio Buarque de Holanda, publicado em 1936. Neste afinco, embora a noção de cordialidade do "homem cordial" seja abordada por Souza, o alvo central da sua crítica é o patrimonialismo. A primeira síntese resultante do empenho é: a crise brasileira atual é também, e antes de tudo, uma crise de ideias. Refere-se aos equívocos que existem nas velhas ideias, que nos legaram o tema da pobreza como culpa, ou desajuste da pessoa pobre, e o da corrupção na política como nosso grande problema nacional. 
Em consonância com Jessé de Souza, as ideias contidas no clássico corroboram para a naturalização da submissão de uma classe social sobre a outra. E deve-se ao resultado da ação combinada de dois fatores: o primeiro é o fato de Sérgio Buarque ter construído uma narrativa totalizadora - como a das religiões que não podem deixar margem, lacunas e dúvidas - do Brasil e de sua história; e o segundo é o de ter criado a legitimação perfeita para uma dominação oligárquica e antipopular, com a aparência de estar fazendo crítica social.

Dessa maneira, Souza (2017) considera que haja tanta influência nas relações sociais do Brasil pela obra de Sérgio Buarque, que isso o motivou a reconstruir uma contraposição às suas ideias ponto a ponto. Entretanto há também crítica a outros escritores e artistas, considerando que "[...] como não somos abelhas nem formigas, mas um tipo de animal que interpreta a própria ação, toda a nossa ação no mundo é influenciada, quer saibamos disso ou não, por ideias. São elas que nos fornecem o material que nos permite interpretar nossa própria vida e dar sentido a ela" (SOUZA, 2017 p. 20). Nosso comportamento é determinado por uma visão do mundo e das coisas construídas. Esse sentido do mundo nos parece natural, dado que nascemos sob a influência dele, e são pessoas amadas e admiradas, em casa, na escola ou na televisão, que nos apresentam a ele, de tal modo que nos aparece como algo confiável.

Percebe-se, desse modo, que o objetivo de Souza (2017), de fato, é criticar as ideias dominantes, não apenas nas suas falhas conceituais, como já fizera em outras abordagens. A proposta é também destrinchar a interpretação histórica da realidade brasileira.

O livro de Sérgio Buarque é, ainda hoje, a leitura dominante do Brasil, seja na sua modernização em seus epígonos mais famosos, como Raymundo Faoro, Fernando Henrique Cardoso ou Roberto DaMatta, seja na sua influência ampla e difusa nos intelectuais de direita e de esquerda do Brasil de hoje em dia. É a influência continuada dessa leitura na cabeça das pessoas que nos faz de tolos (SOUZA, 2017, p. 10).

Portanto a reconstrução histórica, por sua vez, permitirá um diagnóstico muito mais acurado e convincente da própria realidade atual. Assim, Jessé de Souza delimita, nesta análise, três eixos temáticos bem definidos. 
O primeiro toma a experiência da escravidão como a semente de toda a sociabilidade brasileira. Para Souza (2017), muitos falaram de escravidão como se fosse um mero nome, sem eficácia social e sem consequências duradouras, inclusive Sérgio Buarque e seus seguidores - que, em certo sentido, para Jessé de Souza, somos todos nós brasileiros; isto porque "[...] a identidade nacional não é definida pelo seu valor de verdade e sim por sua eficácia na produção de uma comunidade imaginária que se percebe como singular" (SOUZA, 2017 p. 22).

Contudo "[...] compreender a escravidão como conceito é muito diferente, é perceber como ela cria uma singularidade excludente e perversa" (SOUZA, 2017 p. 11). Desse modo, o apelo central é compreender que o processo de escravidão instalou uma determinada cultura de sociabilidade racista no Brasil e se perpetua no tempo, precisamente porque nunca foi efetivamente compreendida nem criticada.

A segunda questão desvela a luta das classes sociais por privilégios e distinções. A batalha por excessos e mordomias que resultou em alianças preconceituosas. Portanto, esclarece, melhor que qualquer outra coisa, o padrão histórico que se repete nas lutas políticas do Brasil moderno. Neste âmbito, ao perceber as classes sociais como construção sociocultural, desde a influência emocional e afetiva da socialização familiar, Souza (2017) afirma que abre um caminho para esclarecer nosso comportamento real e prático no dia a dia como nenhuma outra variável.

A reflexão acima consta como segundo contraponto à tradição inaugurada por Sérgio Buarque e continua sendo arrasadoramente influente até hoje. Tal tradição não percebe a ação das classes sociais, daí que tenham criado o "brasileiro genérico", o "homem cordial" de Sérgio Buarque, ou o homem do "jeitinho brasileiro" para Roberto Augusto DaMatta. É por conta dessa inércia provocada pela força de concepções passadas que pensamos os problemas brasileiros sob a chave do patrimonialismo e do populismo. São, portanto, dois espantalhos criados para tornar possível a aliança antipopular que caracteriza o Brasil moderno desde 1930.

Finalmente, o terceiro eixo temático da análise, que é um diagnóstico, corresponde a uma "necessidade coletiva": libertação das amarras invisíveis das falsas interpretações críticas. Para Souza (2017), precisamos adentrar 
o espaço de uma aventura do espírito, que seria, afinal, o primeiro passo para que não mais repitamos a nossa triste história da exclusão recorrente e golpes de Estado. A aventura a que se refere trata da proposição de algo que seja "novo".

Nesse sentido, vale ressaltar que, para abordar o racismo permeado na obra dos intelectuais brasileiros, que taxam o brasileiro de "vira-lata", o autor pondera a priori que o poder é a questão central de toda sociedade. A razão é simples. É ele quem dirá quem manda e quem obedece, quem fica com os privilégios e quem é abandonado e excluído.

Entretanto, para Souza (2017), o exercício do poder social real tem de ser legitimado. Ninguém obedece sem razão. "No mundo moderno, quem cria a legitimação do poder social que será a chave de acesso a todos os privilégios são os intelectuais" (SOUZA, 2017 p. 13). Sendo assim, Souza alerta: pensemos na operação Lava Jato e em sua avassaladora influência na vida do país, pois a limpeza política que o procurador Deltan Dallagnol - o intelectual da operação - determina para o país é uma mera continuidade de relações sociais atreladas ao racismo e à estigmatização das pessoas pobres, encobertas pela crítica à corrupção. Souza adverte que esta é a legitimação da maneira de refletir influenciada por Sérgio Buarque e Raymundo Faoro, sempre no eco da corrupção, destituído de novas análises críticas.

Nesse sentindo, as ideias do Estado e da política corrupta servem para que se repasse às empresas estatais nossas riquezas do subsolo a baixo custo - nacionais e estrangeiras -, de modo que se apropriem privadamente da riqueza que deveria ser de todos. Esta é a corrupção real. Uma corrupção legitimada e tornada invisível por uma leitura distorcida e superficial de como a sociedade e seus mecanismos de poder funcionam. Por conseguinte, o produto é o "imbecil perfeito", criado quando ele, o cidadão espoliado, passa a apoiar a venda subfaturada desses recursos a agentes privados, imaginando que assim evita a corrupção estatal.

Ressalte-se então que é devido ao exposto até aqui que a crítica às ideias dominantes é tão importante. Conforme o autor, combatê-las é iniciar um processo de aprendizado, para nos libertarmos da situação de imbecilidade e idiotia na qual fomos, todos nós, levados pela estratégia de legitimação do poder real no nosso país. A perpétua estigmatização de pessoas 
negras e pobres reflete a não compreensão do racismo e da pobreza como fenômenos complexos, menos ainda, o subterfúgio da corrupção como um manto que encobre esta complexidade. Nesse âmbito, Souza (2017) pondera que: as ciências sociais também têm seus paradigmas históricos que corroboram para a permanência do efeito escravidão. A modificação mais recente e importante para os objetivos da análise de conjuntura em questão é a passagem do paradigma "racista" para o "culturalista" nas Ciências Sociais.

Nesse sentido, até a década de 1920, o racismo fenotípico, isto é, baseado na cor da pele e nos traços fisionômicos, era reconhecido como ciência tanto internacionalmente como nacionalmente. Era ele quem esclarecia, por exemplo, a questão fundamental de explicar a diferença de desenvolvimento entre os diversos povos. Pouco a pouco, esse tipo de racismo foi criticado e substituído pelo culturalismo. Souza (2017) atenta para o fato de que o culturalismo julgava ter vencido o paradigma racista e tê-lo superado por algo não só cientificamente superior, mas também moralmente melhor.

Pronto! O novo "título" para problematizar o racismo, a mídia no mundo todo repete, reproduz e amplia, como se isso tudo fosse conhecimento real e indisputado. Souza (2017) afirma que a mídia não produz conhecimento. Ela apenas distribui e eventualmente, como no caso do Brasil, em um contexto de total desregulação do trabalho midiático, enfatiza alguns aspectos e encobre outros de acordo com seus objetivos comerciais e políticos. Mas ninguém na mídia "cria conhecimento". O conhecimento percebido como autêntico é sempre produto de especialistas treinados, resguarda o autor. A mídia está condenada a se utilizar desse material. Portanto, a percepção adequada e crítica do conhecimento tido como científico é de suma importância para uma análise conjuntural não só do papel político da mídia, mas das crenças que as pessoas compartilham na vida cotidiana sem defesa alguma contra seus efeitos.

Por conseguinte, a segunda tese de Souza (2017) é a de que o paradigma culturalista é, na verdade, uma falsa ruptura com o racismo científico racial. "Onde reside o racismo implícito do culturalismo? Ora, precisamente no aspecto principal de todo racismo, que é a separação ontológica entre seres humanos de primeira classe e seres humanos de segunda classe" (SOUZA, 2017 p. 16). Justamente por isso, o autor considera, no decorrer 
da análise, o termo "racismo" não apenas no seu sentido mais restrito de preconceito fenotípico ou racial, mas também para outras formas de hierarquizar indivíduos, classes e países. Sempre que o mesmo procedimento e a mesma função de legitimar uma distinção ontológica entre seres humanos forem aplicados, essas hierarquias vão existir. Servem de equivalente funcional do racismo fenotípico, realizando o mesmo trabalho de legitimar pré-reflexivamente a suposta superioridade inata de uns e a suposta inferioridade inata de outros.

E, assim, o culturalismo, falso cientificamente como ele é, cumpre exatamente as mesmas funções do racismo científico da cor da pele. Prestase a garantir uma sensação de superioridade e de distinção para os povos e países que estão em situação de domínio e, desse modo, legitimar e tornar merecida a própria superioridade. Portanto, entre os melhores americanos e europeus, ou seja, aqueles que não são conscientemente racistas, nota-se o esforço "politicamente correto" de se tratar um africano ou um latino-americano como se este fosse efetivamente igual.

O racismo culturalista passa a ser uma dimensão não refletida do comportamento social, seja na relação entre os povos, seja na relação entre as classes de um mesmo país. Nesse sentido, um brasileiro de classe média que não seja abertamente racista também se sente em relação às camadas populares do próprio país como um alemão ou um americano se sente em relação a um brasileiro: ele se esforça para tratar essas pessoas como se fossem gente igual a ele. Desse modo, Souza (2017) assegura que o que antes era ciência passa a ser - por força dos meios de aprendizado, como escolas e universidades; meios de divulgação, como jornais, televisão e cinema - crença compartilhada socialmente.

Por força da legitimidade e do prestígio da ciência, do poder de repetição e do convencimento midiático, as pessoas passam a pensar o mundo de tal modo que favorecem a reprodução de todos os privilégios que estão ganhando. É neste engodo, de certo modo confortável, que segue a elite brasileira, sem pensar em perspectivas novas no contexto da reprodução das relações sociais. Segue renovando o conservadorismo racista.

Neste âmbito, o pressuposto primordial que merece destaque na análise conjuntural de Jessé de Souza é a separação da raça humana entre 
aqueles que têm espírito e aqueles que não o têm, sendo, portanto, animalizados e percebidos como corpos. A distinção entre espírito e corpo é fundamental, porque a instituição mais importante da história do Ocidente, onde se localiza o Brasil, a Igreja Cristã, escolheu como caminho para o bem e para a salvação do cristão a noção de virtude, bem definida por Platão.

Conclui-se, portanto, numa breve pontuação das ideias de Souza (2017), que sua análise pauta significativamente a solidificação mais rigorosa do racismo na sociedade brasileira. O efeito da escravidão persiste nas relações sociais, legitimado por ação institucional, primeiramente religiosa, e depois, na atualidade, pela ação da mídia e da indústria dos bens de consumo cultural, como cinema e livros populares, que, através do processo histórico, criam e sustentam a hierarquia moral, a qual separa também os homens e as mulheres em seres de primeira e de segunda classe, respectivamente, e que ganhou nossos corações e nossas mentes, vale lembrar. 